RESEARCH NOTE

\section{Enterotoxigenic Capacity of Campylobacter coli Strains Isolated from Humans and Bovines}

\section{A Tresierra-Ayala/ ${ }^{+}$, H Fernández*, J Zamora**}

Departamento de Microbiología, Universidad Nacional de la Amazonía Peruana, Casilla Postal 751, Iquitos, Perú *Instituto de Microbiología Clinica, Facultad de Medicina **Instituto de Microbiología, Facultad de Ciencias, Universidad Austral de Chile, Casilla Postal 567, Valdiva, Chile

Key words: Campylobacter coli - ileal loop test enterotoxigenic capacity - pathogenicity - reservoirs

In developing countries, Campylobacter coli and $C$. jejuni are important agents associated with diarrheic syndrome. In Latin America, their isolation rates vary from $0.6 \%$ in Cuba to $23.0 \%$ in Iquitos, in the Peruvian jungle region (H Fernández 1992 J Braz Ass Develop Sci 44: 39-43). However, most of the studies have been done only with C. jejuni, in spite of that $C$. coli has similar importance (T Daikoku et al. 1989 FEMS Microbiol Lett 58: 33-36).

Enterotoxigenic capacity has been identified as a pathogenic mechanism in Campylobacter $(\mathrm{G}$ Ruiz-Palacios et al. 1983 Lancet 2: 250-251, H Fernández \& L Trabulsi 1995 Biol Res 28: 205210). Some researchers have reported that this property is similar in both species (W Johnson \& H Lior 1986 J Clin Microbiol 24: 275-281), however others have determined that the enterotoxigenic capacity of $C$. coli is lower than C. jejuni or this bacterium has not enterotoxic property (T Daikoku et al. 1989 FEMS Microbiol Lett 58: 33-36, C Fricker \& R Park 1989 J Appl Bacteriol 66: 477-490).

\footnotetext{
This work received financial support from Grants Fondecyt 59-89; Fondecyt 217-90 and General Office of Investigation - UNAP.

${ }^{+}$Corresponding author. Fax: 51-94-23.4723

Received 5 February 1996

Accepted 29 March 1996
}

The aim of this study was to evaluate the presence of enterotoxigenic capacity in 15 strains of C. coli isolated from humans (7 strains) and from bovines ( 8 strains), previously maintained under freezing temperature $\left(-35^{\circ} \mathrm{C}\right)$. Using the Lior biotyping scheme (H Lior 1984 J Clin Microbiol 20: 636-640), 3 belonged to biovar I and 12 to biovar II (Table).

TABLE

Distribution of biovars of Campylobacter coli strains studied according to the isolation source and determination of their enterotoxigenic capacity

\begin{tabular}{|c|c|c|c|}
\hline \multirow{3}{*}{ Source } & \multicolumn{2}{|c|}{ Biovars } & \multirow[b]{2}{*}{ Total } \\
\hline & I & II & \\
\hline & TOX/TOT & TOX/TOT & $\overline{\text { TOX/TOT }}$ \\
\hline Human & $1 / 2$ & $3 / 4$ & 4/7 (57.1) \\
\hline Bovine & $1 / 1$ & $5 / 7$ & $6 / 8(75.0)$ \\
\hline Total & $2 / 3(66.7)$ & $8 / 12(66.7)$ & $10 / 15(66.7)$ \\
\hline
\end{tabular}

TOX/TOT: no. of enterotoxigenic strains/no. of strains studied; ( ): \% of strains with enterotoxigenic capacity. The difference between the enterotoxigenic capacity of human and bovine strains was not significant $(p>0.05)$.

The enterotoxigenic capacity was determined by the ligated ileal loop test in rats (S Saha et al. 1988 J Med Microbiol 26: 87-91). A cell-free supernatant of each strain was prepared from a $72 \mathrm{hr}$ culture in Brucella broth incubated at $37^{\circ} \mathrm{C}$ in microaerophilic conditions and $500 \mu \mathrm{l}$ were innoculated individually into single 5-cm-long ligated ileal loops of adult Holtzman rats (170 to $250 \mathrm{~g}$ ). Sterile Brucella broth and the cell-free supernatant of a known enterotoxigenic $C$. coli strain were used as negative and positive control, respectively. After $18 \mathrm{hr}$, the animals were killed by ether overdose and the ileum was examined. Distention of the loops with fluid accumulation was considered as a positive result $(98 \mu \mathrm{l} / \mathrm{cm}$ of intestine or more, as determined by Student's t test). The volume/length ratio in negative control was consistently $<20 \mu \mathrm{l} / \mathrm{cm}$. The tests were done in two rats simultaneously.

The enterotoxigenic capacity was determined in $66.7 \%$ of the strains, belonging two strains to the biovar I and eight to the biovar II. Some investigators have reported rates higher than our values. H Bok et al. (1991 J Clin Microbiol 29: 12621264) and W Johnson and H Lior (1986 J Clin Microbiol 24: 275-281) determined rates of 100\% and $83.2 \%$, respectively.

Moreover, our results showed that $57.1 \%$ of the culture supernatants of human strains and $75 \%$ of the supernatants of bovine strains produced fluid 
accumulation. They are in agreement with the results reported in England by $\mathrm{C}$ Fricker and R Park (1989 J Appl Bacteriol 66: 477-490) because in both studies, the difference between the human and bovine strains, in relation to their enterotoxigenic capacity, was not significant ( $>0.05)$. Consequently, this characteristic was not associated with the biovar neither with the strains source.

The presence of enterotoxigenic strains in bovines increases the evidences that these animals could be an important infection source for humans. Some authors have expressed that in developing countries, the close association between man and animals may lead to a cycle of infection that would increase the toxigenicity of Campylobacter strains by consecutive passages through the intestinal tract (S Saha et al. 1988 J Med Microbiol 26: 87-91). A similar enhancement of other pathogenic factors of Campylobacter has been suggested by D Newell et al. (1985 J Hyg 94: 45-54).

The present study suggests that the enterotoxigenicity could be an important pathogenic mechanism by which $C$. coli may produce disease. For this reason we consider that this bacterium must have the same importance as $C$. jejuni in relation to their enterotoxigenicity. 